\title{
Underutilization of acetylsalicylic acid for acute coronary syndromes in the emergency department
}

\author{
François Dufresne, MD; ${ }^{*}$ Danielle Blouin, MD $;^{\dagger}$ Xiaoqing Xue, MSc; ${ }^{\ddagger}$ Marc Afilalo, $\mathrm{MD}^{\S}$
}

\begin{abstract}
Objective: Acetylsalicylic acid (ASA) is a simple and cost-effective treatment for acute coronary syndromes (ACS). Our objectives were to determine the frequency of ASA administration in the emergency department (ED) for patients with acute myocardial infarction or unstable angina, and to identify patient characteristics associated with its administration.

Methods: This is a retrospective chart review of patients discharged with a final diagnosis of ACS. Data on age, gender, mode of presentation, presence of chest pain at triage, administration of ASA or not in the ED, dosage and form of ASA received, timing of administration, presence of contraindications to ASA and use of regular ASA prior to ED presentation were recorded.

Results: Six hundred and one charts were analyzed. Five hundred and fifty patients $(91.5 \%)$ received ASA. Only 444 (73.9\%) of these 550 patients were administered the ASA appropriately, according to the American Heart Association / American College of Cardiology (AHAACC) guidelines. Univariate analysis showed that chart notes "Transport by ambulance," "Allergy to ASA" and "Gastrointestinal bleed" were associated with a lower probability of the patient being administered ASA. If a patient was noted as taking ASA regularly, it increased the chance of this patient being administered ASA in the ED.

Conclusion: Although the study ED performed well, administering ASA to $91.5 \%$ of patients with ACS, only $73.9 \%$ of the patients who received ASA were administered the ASA appropriately, as recommended in the AHA/ACC guidelines. Educational strategies and system changes are necessary to increase the proportion of eligible ACS patients who receive appropriate ASA therapy.
\end{abstract}

Key words: acetylsalicylic acid; ASA; acute coronary syndromes; acute myocardial infarction; unstable angina

\begin{abstract}
RÉSUMÉ
Objectif : L'acide acétylsalicylique (AAS) est un traitement simple et économique pour le syndrome coronarien aigu (SCA). Nos objectifs étaient de déterminer la fréquence d'administration de I'AAS au département d'urgence (DU) pour des patients atteints d'un infarctus aigu du myocarde ou d'angine instable et d'identifier les caractéristiques des patients associées à son administration.

Méthodes: Il s'agit d'une revue rétrospective de dossiers de patients ayant reçu leur congé avec un diagnostic final de SCA. Les données sur l'âge, le sexe, le mode de présentation, la présence de douleur à la poitrine lors du triage, l'administration d'AAS ou non au DU, la posologie et la forme
\end{abstract}

\footnotetext{
*Emergency Department, McGill University Health Centre, Montréal, Que.

†Previously from the Emergency Department, Jewish General Hospital, McGill University, Montréal, Que.; now at Department of Emergency Medicine, Queen's University, Kingston, Ont.

¥Statistician, Emergency Medicine Research Department, Jewish General Hospital, McGill University, Montréal, Que.

§Chief, Emergency Department, Jewish General Hospital, McGill University, Montréal, Que.
}

Received: Jan. 22, 2004; final submission: May 10, 2004; accepted: May 20, 2004

This article has been peer reviewed.

Can J Emerg Med 2004;6(5):333-6 
d'AAS reçues, le moment de l'administration, la présence de contre-indications à l'usage de l'AAS et I'usage d'AAS régulier avant la visite au DU furent notées.

Résultats : Six cent un dossiers furent analysés. Cinq cent cinquante patients $(91,5 \%)$ reçurent de I'AAS. Seulement $444(73,9 \%)$ de ceux-ci reçurent un traitement adéquat à l'AAS, selon les recommandations de l'American Heart Association/American College of Cardiology (AHA/ACC). Une analyse univariée démontra que les notes au dossier "Transport en ambulance», "Allergie à I'AAS», et "Hémorragie gastro-intestinale» étaient associées à une probabilité plus faible pour le patient de recevoir de I'AAS. Si les notes indiquaient que le patient prenait de I'AAS sur une base régulière, ses chances de recevoir de I'AAS au DU augmentaient.

Conclusion: Bien que le DU à l'étude se soit bien acquitté de sa tâche, administrant de l'AAS à $91,5 \%$ des patients atteints d'un SCA, seulement 73,9 \% des patients reçurent un traitement adéquat à I'AAS, selon les recommandations de I'AHA/ACC. Des stratégies d'enseignement et des modifications du système sont nécessaires afin d'augmenter la proportion de patients atteints d'un SCA admissibles qui reçoivent un traitement à I'AAS adéquat.

\section{Introduction}

Cardiovascular diseases remain the most important causes of death in Canada. ${ }^{1}$ Early administration of acetylsalicylic acid (ASA) reduces fatal and non-fatal complications in patients with acute coronary syndromes (ACS), and ASA is considered critical in ACS management. ${ }^{2-8}$ The American College of Cardiology and the American Heart Association (ACC/AHA) recommended 160 to $325 \mathrm{mg}$ of non-enteric coated ASA for emergency department (ED) patients with suspected ACS. ${ }^{6,7}$

Despite proven benefit of this intervention, several studies have reported sub-optimal ASA use in the ED treatment of acute myocardial infarction. ${ }^{9-14}$ We postulated that the proportion of ACS patients receiving recommended doses of ASA is lower than that reported in previous literature. Our objective was to determine the rate of adherence to recommended ASA guidelines in our institution and to define patient characteristics associated with higher and lower rates of ASA administration. This information would be useful in devising strategies to improve compliance with ASA administration guidelines.

\section{Methods}

\section{Setting and patients}

This retrospective study was conducted in a 650-bed academic tertiary care centre, in Montréal, Que., with an annual ED census of over 60000 visits. At the time of the study, Montréal emergency medical services attendants were not authorized to administer medications and there were no explicit protocols or standing orders for ASA administration in ED patients with ACS.

Eligible subjects included all patients discharged from the study hospital between June 1, 1999, and Oct. 30, 2000, with a primary diagnosis of ACS. International Classification of Diseases, 9th rev (ICD-9) codes for Q- wave my- ocardial infarction (MI), non-Q wave MI, unstable angina and ACS were used to identify eligible patients and select charts for review. Patients were excluded if they were under 18 years of age, if they were not admitted through the ED, or if they were transferred from other health centres.

\section{Data collection}

One research assistant and the principal investigator (F.D.) extracted the following data elements from each patient chart onto standard data collection forms: age, gender, mode of presentation (ambulance or not), presence of chest pain at triage, administration of ASA (dose, form, timing), contraindications to ASA (allergy or active gastrointestinal [GI] bleed), and whether patients were already taking ASA on a regular basis prior to presentation. Documentation of melena, hematemesis or hematochezia at the time of presentation, and results of occult blood testing in the stools, were used as evidence of GI bleed.

Documentation of ASA administration was looked for on the triage sheet where initial ED medications are recorded, in the ED nursing cardex, where nurses document medications administered later during the ED stay, in the medical orders written by physicians, and in the ED progress notes. Time-to-medication was calculated as the interval from first assessment by the triage nurse (as recorded on the triage sheet) to the time of ASA administration. Patients who were not administered ASA until more than 24 hours after ED arrival were not considered for this study. To assess reliability of the data collection process, a random sample of 23 charts was abstracted by both data collectors, and interobserver agreement was determined.

\section{Data analysis}

Descriptive statistics, including means and proportions are presented, and confidence intervals (CIs) for proportions were calculated using asymptotic normal estimation. Uni- 
variate analysis was performed for each independent variable to calculate unadjusted odds ratios (ORs). Multiple variable logistic regression analysis identified the variables most strongly associated with ASA administration. This study was approved by our hospital's investigation review board.

\section{Results}

During the study period, 672 patients were discharged from the hospital with a diagnosis of ACS; 71 were excluded from the study because they had been transferred from other institutions. Acute myocardial infarction was the most common diagnosis, seen in $47.8 \%$ of patients. Of the 601 eligible subjects, 550 (91.5\%) received ASA in the ED; however, $94(17.1 \%)$ of the 550 patients received enteric-coated ASA, 12 (2.2\%) were given less than $160 \mathrm{mg}$, and 51 were not administered ASA at all. Consequently, only $444(73.9 \%)$ patients were treated in the ED according to the AHA/ACC ASA administration guidelines. In this group of 157 patients who were not treated according to the AHA/ACC recommendations for the administration of ASA in ACS, 86 (54.8\%) were on regular daily ASA and $2(1.3 \%)$ received ASA en route to the ED. Of the 51 patients who did not receive ASA at all, only 10 (19.6\%) had documented contraindications (GI bleed or allergy).

Mean time to medication in patients who received ASA was 189 minutes (95\% CI 168-210 min), and the median time was 91 minutes (Fig. 1). The modal ASA dose was $160 \mathrm{mg}$, given in 425 patients $(77.3 \%)$. Ten patients were given ASA despite documented contraindications, with no reported adverse outcomes.

Table 1 contrasts patients who received ASA to those who did not. Logistic regression analysis suggests that ambulance transport, ASA allergy and GI bleed were associated with a lower probability of receiving ASA, whereas being on regular ASA was associated with a greater chance of receiving ASA. Patients over 75 years of age were less likely

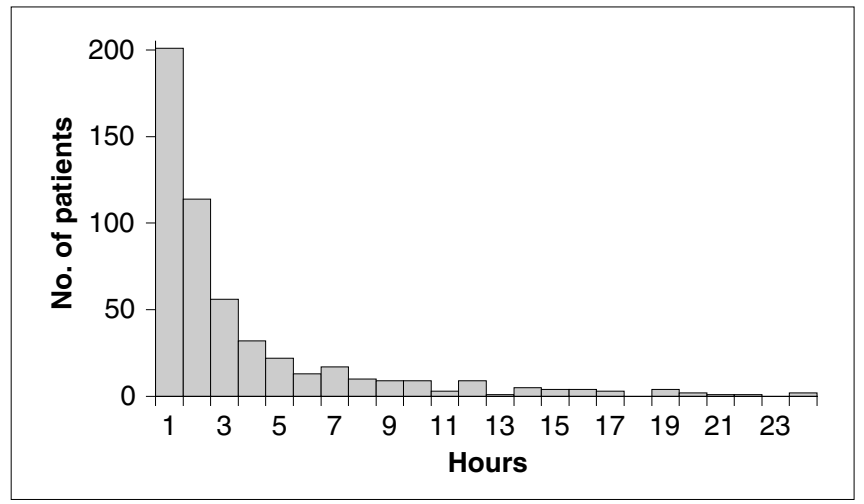

Fig. 1. Timing of ASA administration to receive ASA (adjusted OR $=0.44 ; 95 \%$ CI $0.24-0.81$ ).

Interobserver reliability assessment for data extraction on a random sample of 23 charts showed $96.3 \%$ agreement on 299 total variables.

\section{Discussion}

Our study shows that a substantial proportion of eligible ACS patients do not receive ASA according to current recommendations. This is consistent with prior studies reporting sub-optimal ASA use in the ED. -12-14 $^{-12}$

In our study, 550 (91.5\%) patients received ASA in ED. This places our ED among the best performers when compared with published literature. However, a more detailed analysis of ASA doses and formulations revealed that AHA/ACC recommendations were followed for only 444 (73.9\%) of these 550 patients. Among the 157 patients who did not receive ASA as per guidelines, 86 were on regular daily ASA and 2 received ASA en route to the ED. Since ASA antiplatelet effect lasts 10 days, ${ }^{15}$ one could argue that the 86 patients already on ASA and the 2 patients who received ASA en route to the ED did not require additional ASA in the ED. In this more forgiving analysis, only 69 patients (11.5\%) failed to receive appropriate ASA therapy.

Our data illustrate that studies and quality initiatives assessing ASA use for patients with ACS should consider not only whether ASA was given, but whether an appropriate dose and formulation was given. Previous studies have failed to do so, hence may overestimate the proportion of

Table 1. Potential clinical predictors for ASA administration in the emergency department (ED)

\begin{tabular}{|c|c|c|c|}
\hline \multirow[b]{2}{*}{ Patient characteristics } & \multicolumn{2}{|c|}{$\begin{array}{l}\text { No. (and \%)* } \\
\text { of patients }\end{array}$} & \multirow[b]{2}{*}{$\begin{array}{l}\text { Odds } \\
\text { ratio }\end{array}$} \\
\hline & $\begin{array}{l}\text { ASA given } \\
\text { in the ED } \\
(n=550)\end{array}$ & $\begin{array}{c}\text { ASA } \\
\text { not given } \\
\text { in the ED } \\
(n=51)\end{array}$ & \\
\hline Age in years & 71.0 & 74.6 & \\
\hline Male gender & $325(59.1)$ & $26(51.0)$ & 1.39 \\
\hline $\begin{array}{l}\text { Arrival by } \\
\text { ambulance }\end{array}$ & $228(41.5)$ & $29(56.9)$ & 0.54 \\
\hline \multicolumn{4}{|l|}{ Diagnosis } \\
\hline AMI & $257(46.7)$ & $30(58.8)$ & 0.61 \\
\hline Unstable angina & 247 (44.9) & $16(31.4)$ & 1.78 \\
\hline Unspecified ACS & $46(8.4)$ & $5(9.8)$ & 0.84 \\
\hline Chest pain at triage & $446(81.1)$ & $38(74.5)$ & 1.47 \\
\hline Regular ASA user & $254(46.2)$ & $15(29.4)$ & 2.06 \\
\hline Allergic to ASA & $5(0.9)$ & $5(9.8)$ & 0.08 \\
\hline GI bleed & $5(0.9)$ & $5(9.8)$ & 0.08 \\
\hline $\begin{array}{l}\text { ASA = acetylsalicylic acid; AM } \\
\text { coronary syndromes; } \mathrm{GI}=\text { gas } \\
{ }^{*} \text { Except where otherwise indi }\end{array}$ & $\begin{array}{l}\text { cute myocardia } \\
\text { itestinal }\end{array}$ & rction; ACS & \\
\hline
\end{tabular}


patients who receive appropriate therapy. ${ }^{6,8}$

Although we have known for over 2 decades that ASA is beneficial, this study shows there is still room for improvement. Educational strategies aimed at increasing the number of eligible patients receiving ASA should be developed, with an emphasis on older patients and those presenting by ambulance. Triage nurse and paramedic ASA administration protocols might further improve the proportion of patients receiving ASA. Refresher sessions on the importance of ASA in ACS management and wide distribution of current guidelines to nurses, attending ED physicians and house staff could help standardize ASA utilization patterns.

\section{Limitations}

This study reports the practice of a single ED; it may not be reflective of all settings. A second limitation concerns the location of ASA administration. We considered any ASA administered within 24 hours of the patient's arrival as "given in the ED." At our institution, ED nurses and inpatient nurses use the same cardex system, and it is possible that some ASA was actually given on the ward or in the cardiac care unit rather than in the ED. Our conclusions may therefore overestimate the proportion of patients who received ASA in the ED.

We chose to rely on hospital discharge diagnosis as opposed to ED diagnosis of ACS. It is possible that some patients did not receive ASA in the ED because the diagnosis of ACS was not suspected in the ED or because the ACS event occurred after the patient left the ED.

\section{Conclusion}

Although this ED performed well, administering ASA to 91.5\% of patients with ACS, only $73.9 \%$ received ASA as recommended in the AHA/ACC guidelines. Educational strategies and system changes are necessary to increase the proportion of eligible ACS patients who receive appropriate ASA therapy.

\section{Competing interests: None declared.}

Acknowledgement: We thank Mrs. Orit Moore for her help with chart review and the Research Division of the Jewish General Hospital, Montréal, Que., for their support.

\section{References}

1. Filate WA, Johansen HL, Kennedy CC, Tu JV. Regional variations in cardiovascular mortality in Canada. Can J Cardiol 2003; 19(11):1241-8.

2. Second International Study of Infarct Survival (ISIS-2) Collaborative Group. Randomised trial of intravenous steptokinase, oral aspirin, both, or neither among 17,187 cases of suspected acute myocardial infarction. Lancet 1988;2:349-60.

3. Cairns JA, Gent M, Singer J, Finnie KJ, Froggatt GM, Holder
$\mathrm{D}$, et al. Aspirin, sulfinpyrazone, or both in unstable angina. $\mathrm{N}$ Engl J Med 1985;313:1369-75.

4. Théroux P, Ouimet H, McCans J, Latour JG, Joly P, Lévy G, et al. Aspirin, heparin or both to treat acute unstable angina. $\mathrm{N}$ Engl J Med 1988;319:1105-11.

5. Lewis HD, Davis JW, Archibald DG, Steinke WE, Smitherman TC, Doherty JE, et al. Protective effects of aspirin against acute myocardial infarction and death in men with unstable angina: results of a veterans administration cooperative study. N Engl J Med 1983;309:396-403.

6. Ryan TJ, Antman EM, Brooks NH, Califf RM, Hillis LD, Hiratzka LF, et al. 1999 Update: ACC/AHA guidelines for the management of patients with acute myocardial infarction: executive summary and recommendations: a report of the American College of Cardiology/American Heart Association Task Force on Practice Guidelines (Committee on Management of Patients With Myocardial Infarction). Circulation 1999;100:1016-30.

7. Braunwald E, Antman EM, Beasley JW, Califf RM, Cheitlin $\mathrm{MD}$, Hochman JS, et al. ACC/AHA guidelines for the management of patients with unstable angina and non-ST-segment elevation myocardial infarction: executive summary and recommendations: a report of the American College of Cardiology /American Heart Association Task Force on Practice Guidelines (Committee on Management of Patients With Unstable Angina. Circulation 2000;102:1193-209.

8. Braunwald E, Antman EM, Beasley JW, Califf RM, Cheitlin MD, Hochman JS, et al. ACC/AHA 2002 guideline update for the management of patients with unstable angina and non-st-segment elevation myocardial infarction: a report of the American College of Cardiology/American Heart Association Task Force on Practice Guidelines (Committee on Management of Patients With Unstable Angina). 2002. Available at: www.acc.org/clinical /guidelines/unstable/unstable.pdf (accessed 2004 July 2).

9. Saketkhou BB, Conte FJ, Noris M, Tilkemeier P, Miller G, Forman DE, et al. Emergency department use of aspirin in patients with possible acute myocardial infarction. Ann Intern Med 1997;127(2):126-9.

10. Krumholz HM, Radford MJ, Ellerbeck EF, Hennen J, Meehan TP, Petrillo M, et al. Aspirin in the treatment of acute myocardial infarction in elderly Medicare beneficiaries. Circulation 1995;92:2841-7.

11. Frilling B, Schiele R, Gitt AK, Zahn R, Schneider S, Glunz HG, et al. Characterization and clinical course of patients not receiving aspirin for acute myocardial infarction: results from the MITRA and MIR studies. Am Heart J 2001;141(2):200-5.

12. Soumerai SB, McLaughlin TJ, Gurwitz JH, Pearson S, Christiansen CL, Borbas C, et al. Timelines and quality of care for elderly patients with acute myocardial infarction under Health Maintenance Organization vs. Fee-for-Service insurance. Arch Intern Med 1999;159:2013-20.

13. McLaughlin TJ, Soumerai SB, Willison DJ, Gurwitz JH, Borbas C, Guadagnoli E, et al. Adherence to national guidelines for drug treatment of suspected acute myocardial infarction. Arch Intern Med 1996;156;799-805.

14. Burt CW. Summary statistics for acute cardiac ischemia and chest pain visits to United States EDs, 1995-1996. Am J Emerg Med 1999;17:552-9.

15. Patrono C, Coller B, Dalen JE, FitzGerald GA, Fuster V, Gent $\mathrm{M}$, et al. Platelet-active drugs : the relationships among dose, effectiveness, and side effects. Chest 2001;119 (1 Suppl):39S-63S.

Correspondence to: Dr. François Dufresne, Emergency Department, Montreal General Hospital, 1650, ave. Cedar, Montréal QC H3G 1A4; 514934 6011, fdufresne@sympatico.ca 